\title{
Preparation of Activated Carbon Derived From Xanthoceras sorbifolium Bunge and its Electrochemical Properties
}

\author{
Ruiyao Yao ${ }^{1.2}$, Zhiqian Li ${ }^{1.2}$, Hongli Gao ${ }^{1.2}$, Guoying Wang ${ }^{1.2}$, Gaofeng Shi ${ }^{1.2 *}$ \\ ${ }^{1}$ School of Petrochemical Engineering, Lanzhou University of Technology, Lan gong ping Road, \\ Lanzhou, Gansu, China \\ ${ }^{2}$ Key Laboratory of Low Carbon Energy and Chemical Engineering of Gansu Province \\ *E-mail: 971584796@qq.com
}

Received: 2 October 2021 / Accepted: 10 November 2021 / Published: 6 December 2021

\begin{abstract}
Porous carbon was the reside of Xanthoceras sorbifolium Bunge oil after pressing as carbon source and zinc chloride as activator. Multistage porous carbon was prepared. The chemical and physical properties of porous carbon materials were characterized by transmission electron microscopy (TEM), scanning electron microscopy (SEM), X-ray diffraction (XRD), nitrogen adsorption/desorption, Raman spectroscopy and XPS. Nitrogen adsorption/desorption experiments show that $\mathrm{ZnCl}_{2}$ has good pore expansion, with a total pore volume of $0.68 \mathrm{~cm} 3 / \mathrm{g}$ and a maximum specific surface area of 1079.79 $\mathrm{m} 2 / \mathrm{g}$. At $1 \mathrm{~A} / \mathrm{g}$ current density, the specific capacitance is $220 \mathrm{~F} / \mathrm{g}$. The results show that multistage carbon is one of the ideal electrode materials for supercapacitors.
\end{abstract}

Keywords: electrochemical properties; xanthoceras sorbifolia; porous carbon

\section{FULL TEXT}

(C) 2022 The Authors. Published by ESG (www.electrochemsci.org). This article is an open access article distributed under the terms and conditions of the Creative Commons Attribution license (http://creativecommons.org/licenses/by/4.0/). 